\title{
Estimation of shear wave velocity from SPT N-value - field assessments
}

\author{
Jaykumar Shukla ${ }^{\text {i) }}$, Deepankar Choudhury ${ }^{\text {ii) }}$ and Dhananjay Shah ${ }^{\text {iii) }}$
}

\begin{abstract}
i) Senior Geotechnical Engineer, L\&T-Sargent \& Lundy Ltd., Vadodara, India. E-mail: Jaykumar.Shukla@Lntsnl.com ii) Professor, Dept. of Civil Engineering, IIT Bombay, Powai, Mumabi 400076. E-mail: dc@civil.iitb.ac.in

iii) Professor, Dept. of Applied Mechanics, M.S. University of Baroda, Vadodara, India. E-mail: dr_dlshah@yahoo.com
\end{abstract}

\begin{abstract}
A key parameter necessary to properly evaluate dynamic response of soil is shear modulus. The shear modulus is usually estimated by using shear wave velocity (Vs) of soil measured through in situ geophysical tests. Since the shear modulus is the key parameter for geotechnical earthquake engineering problems both quantitatively and qualitatively, its measurement shall be done precisely. However, in many cases, shear wave velocity is estimated through field test like SPT N-value of soil whenever the precise measurement of Vs is not available. There are many empirical equations exist worldwide which correlate soil type and SPT N-value with expected shear wave velocity. However, all these equations are developed based on some field measurements limited to selected sites and geology. In the present paper, actual shear wave velocity measurements for five different project sites are compared with that estimated using 22 soil specific correlations including correlations recommended for Indian soil sites. The selected five project sites represent different parts of India i.e. Gujarat, Punjab, Andhra Pradesh, Uttar Pradesh, consist of different geologic origins. Present study review available correlations and highlights that shear wave velocity estimated through available correlations differ largely with actual measured data. Since, the measurement of SPT $\mathrm{N}$-value depends upon many factors, the direct measurement of shear wave velocity using correlations may not converge for actual engineering applications for many sites. The actual measured data along with SPT N-value measurement data are presented in the paper.
\end{abstract}

Keywords: Shear wave velocity, SPT N-value, geophysical measurement

\section{INTRODUCTION}

Shear modulus is one of the most important parameter in dealing with geotechnical earthquake engineering aspects, including earthen structures, deep foundation systems, soil-structure interaction, machine foundations, and free-field ground response. However, in absence of direct measurement of $\mathrm{G}$, it is estimated through in-situ measured shear wave velocity (Vs). However, the determination of shear wave velocity at field is not easy task and mostly depends upon project and feasibility for measurements. For green field projects, during project feasibility stage, these tests are usually skipped to limit the cost of ground investigations. In brown filed projects, available space and running facilities may not allow to take the test at required locations. In such situations, engineers opt for empirical correlations between shear wave velocity (Vs) and reliable static field test data like standard penetration test (SPT) $\mathrm{N}$ value, CPT values etc., to estimate shear wave velocity or dynamic soil parameters.

\section{PREVIOUS STUDIES}

The Several researchers in the have established empirical correlations between popular field test results (i.e. uncorrected SPT N-value) based on the measured response at specific sites. Many Indian researchers like Hanumanthrao and Ramana (2008), Maheshwari et al. (2010), Thaker and Rao (2011) and Chatterjee and Choudhury (2013) also established such type of empirical correlations of shear wave velocity with both uncorrected and corrected SPT N-values for various categories of soil (i.e. all soils, sand and clay). These correlations are useful for seismic hazard analysis and other related seismic studies at a particular locality by considering the dynamic geotechnical properties through the use of field test data as highlighted by researchers like Mhaske and Choudhury (2010), Shukla and Choudhury (2012). Jafari et al. (2002) established statistical correlations between SPT N-values and shear wave velocity for clayey soils, silty soils and fine-grained soils for Tehran city. Hasancebi and Ulusay (2007) developed correlations between shear wave velocity measured by seismic refraction method and SPT blow count for the Marmara region of Turkey. Ninety-seven data pairs were considered by the authors, and correlations for all soils, sandy soils and clayey soils were developed using regression analysis for both 
raw and energy-corrected SPT N-values. Dikmen (2009) proposed statistical correlations between shear wave velocity and SPT N-value for all soils, sand, silt and clay for western central Anatolia region of Turkey. Other empirical correlations between shear wave velocity and SPT N-values have been proposed by Seed and Idriss (1981), Pitilakis et al. (1992) and many others.

Many empirical correlations are existing, however, it is very difficult to rate one over another since confidence level of the each correlation vary site to site. In present study, SPT N-value and shear wave velocity data of five project sites are reviewed in order to compare actual measured values with estimated through these correlations. Five representative sites from various parts of India are selected in order to include available soil types in India. Respective locations of the selected 5 sites are illustrated in Fig. 1. Empirical correlations recommended by Seed and Idriss (1981); Jafari et al. (2002); Hasancebi and Ulusay (2007); Hanumanthrao and Ramana (2008); Dikmen (2009); Maheshwari et al. (2010); Mhaske and Choudhury (2011); Thaker et al. (2011); Anbazhagan et al. (2013) and Chatterjee and Choudhury (2013) are selected for estimation of shear wave velocity from uncorrected SPT N-value data for different categories of soils (all soils, clay, silt and silty sand). It may be noted that for Indian sites, such comparisons are not available at present and present study provided opportunity to validate these recommended correlations and give insight to practicing engineers regarding performance of these correlations.

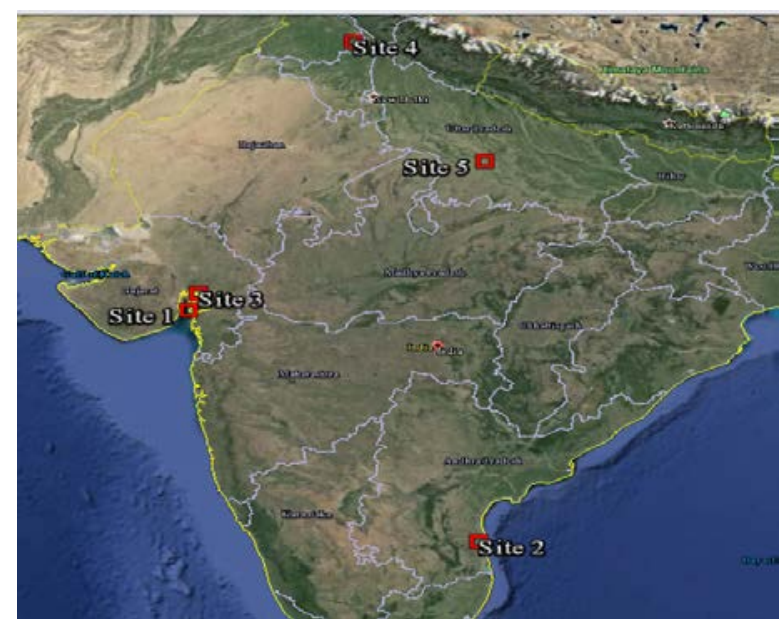

Fig. 1. Respective locations of selected sites within India

\section{STUDY SITES}

Site 1 is located near Dahej area of the Gujarat state in the western part of India which is the most modern commercial port and storage terminal located at Gujarat state (District: Bharuch), in the Gulf of Khambhat (Cambay) on the west coast of India. The location also represents some Industrial facilities within the Dahej area including some existing and future port facilities.
Water table at the site is high and usually observed to be close to natural ground level due to vicinity of the sea. Site 2 is located on southern part of India and is identified for development of a super critical thermal power plant in Andhra Pradesh state of India in order to cater future energy requirements. Water table at site is observed to be 5 to $6 \mathrm{~m}$ from the ground level. Site 3 is state owned, oil and gas based power project site in Gujarat state of India near Gulf of Khambhat. Water table at site is $16 \mathrm{~m}$ below natural ground level. Site 4 is at $1400 \mathrm{MW}$ Rajpura Thermal Power Plant in Punjab state of India. Site consists of interbeded layers of low plastic silty clay and clayey silt having SPT in range of 15 to 25 up to $23 \mathrm{~m}$. The water table is below $15 \mathrm{~m}$ from the natural ground level at the time of investigation. Site 5 is at IIT Kanpur in U.P. state of India, which is situated within the flood plain of the Ganga as described by Jishnu et al. (2012). The site is mainly composed of silty sand and clayey soils. The SPT- N value for the Site varies from 10 to 24, indicating that the soils are loose to moderately dense. The observed SPT N-values for selected sites are presented in Fig. 2.

\section{SHEAR WAVE VELOCITY ESTIMATION}

The shear wave velocity (Vs) for each site is estimated through 22 correlations proposed by various researchers as discussed in previous sections by using SPT N-values. The SPT N-values recorded at each depth for each site is used as input to estimate shear wave velocity using correlations. It is important to note that for Site 1 and Site 5, Vs is actually measured using downhole test method and for other sites crosshole test were employed. The estimated Vs and actually measured Vs are presented in the Figs. 3 to 7.

It is important to note that all the empirical correlations used for estimation of shear wave velocity are well researched and validated using field data. However, all correlations are site specific and it is important to check them for soils from different geologic origin and formations. In order to compare the estimated shear wave velocity among various correlations, average shear wave velocity approach is selected for the present study. The average shear wave velocity for each site is estimated using ASCE/SEI 7-05.

Based on comparison of average shear wave velocities (Figs. 3 to 7 ) it is important to note that for Site 1 , it is observed that all the correlations overestimates the shear wave velocity compared to actual measured response. For Site 2, correlations given by Chatterjee and Choudhury (2013) (All soils, silty sand and clay), Thaker and Rao (2011) (Clay), Maheshwari et al. (2010) (All soils and sand), Seed and Idriss (1984) gives better results. whereas for Site 3, Maheshwari et al. (2010) (Sand), Dikmen (2009) (Clay), Thaker and Rao (2011) (Sand) observed to fit better results. For Site 4, Thaker and Rao (2011) (Clay), 
Maheshwari et al. (2010) gives better estimate and for Site 5, Maheshwri et al. (2010) (Clay), Seed and Idriss (1981), Chatterjee and Choudhury (2013) (Silty Sand) predicts closely. In all cases, the correlations given by Anbazhagan et al. (2013) overestimated the shear wave velocity prediction.

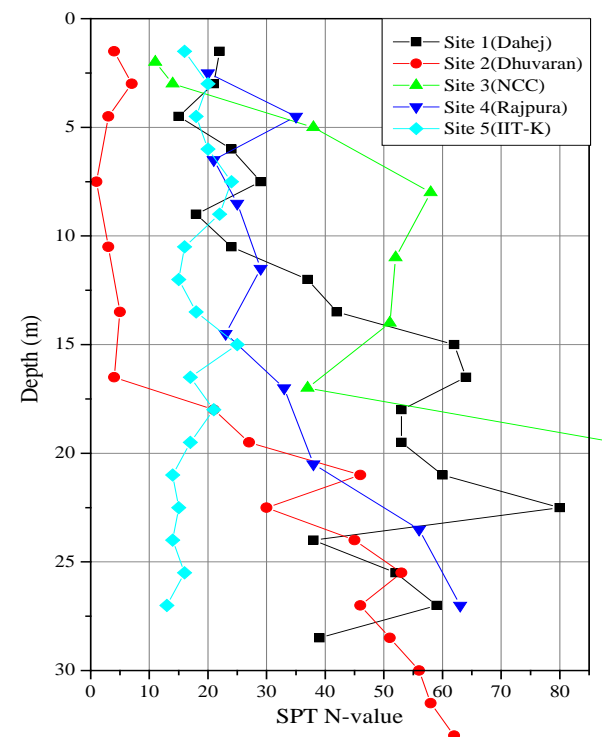

Fig. 2. Observed SPT N-values at selected sites

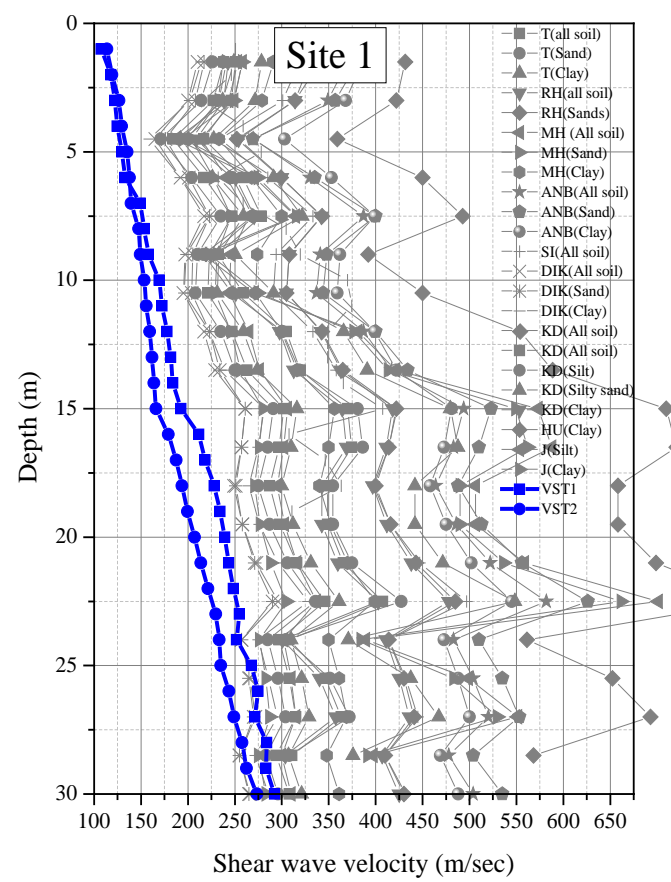

Fig. 3. Comparison of shear wave velocity estimated from SPT $\mathrm{N}$-value and measured response (Site 1).

It is important to note that soft and silty clays exhibit very low blow counts i.e. Site 3 , and the standard penetration test is known to be a very poor predictor of the engineering properties of soft clays. It is therefore very difficult to identify a single correlation which can provide reasonably accurate estimate of shear wave velocity from SPT N-value. The water table level at site, the method of measurement of SPT N-value, geological origin of the soil and their inter-bedding of the layers influence the SPT N-values largely and thereby influencing the estimated shear wave velocity also. It is also imperative to note that shear modulus and Vs are small strain properties measured at shear strains on the order of $10-3 \%$ or less. SPT tests are typically large-strain measurements associated with failure of the soil surrounding the SPT sampler.

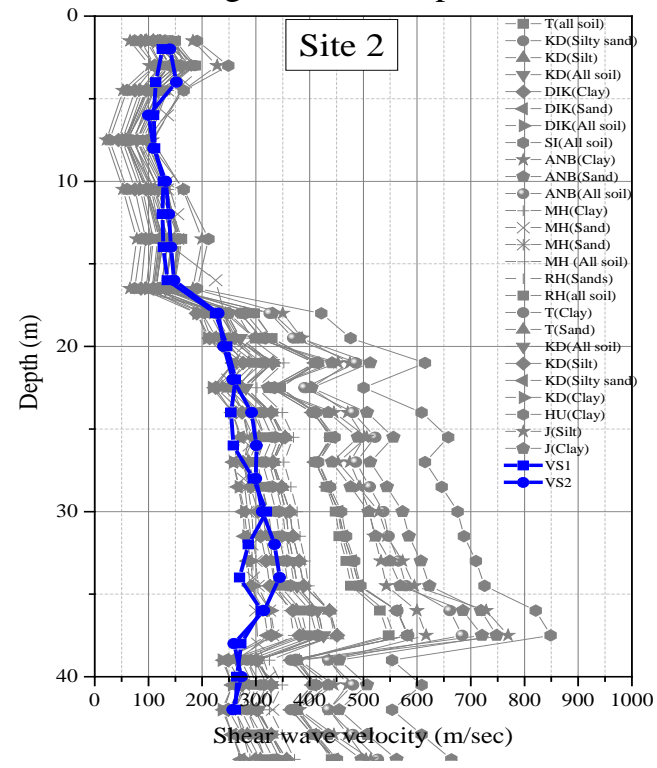

Fig. 4. Comparison of shear wave velocity estimated from SPT $\mathrm{N}$-value and measured response (Site 2).

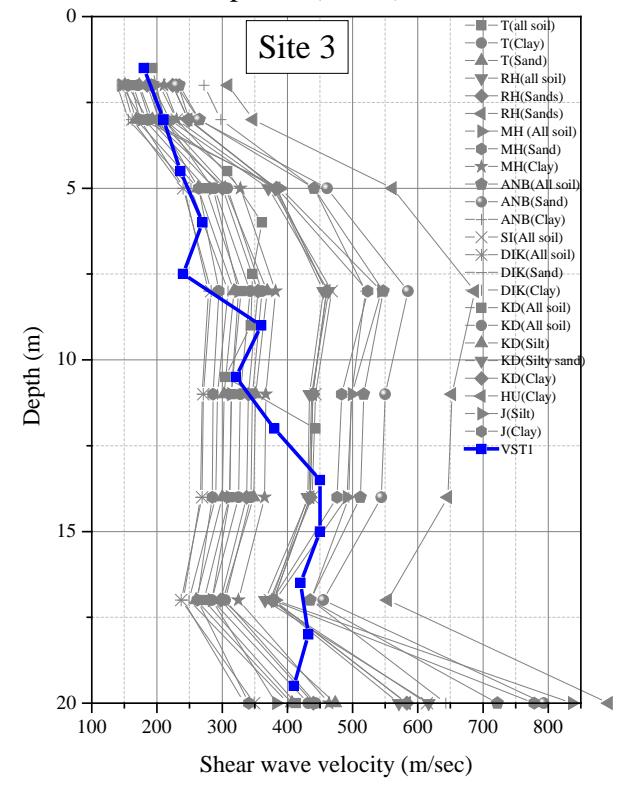

Fig. 5. Comparison of shear wave velocity estimated from SPT $\mathrm{N}$-value and measured response (Site 3).

\section{CONCLUSIONS}

In the present study, geotechnical borehole data were collected from five project sites across India. An attempt has been made to verify the applicability of empirical correlations between uncorrected SPT N values with shear wave velocity (Vs). Present study reveals that no single correlation can be used reliably for estimation of shear wave velocity for a given profile. 
It is observed that for some sites, it may be completely misleading to estimate the shear wave velocity based on the empirical correlations from SPT N-value observations i.e. for Site 1.

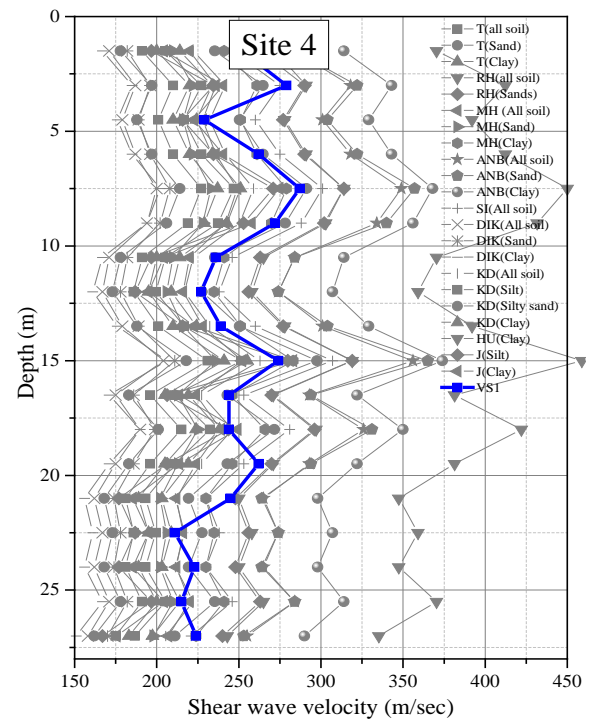

Fig. 6. Comparison of shear wave velocity estimated from SPT $\mathrm{N}$-value and measured response (Site 4).

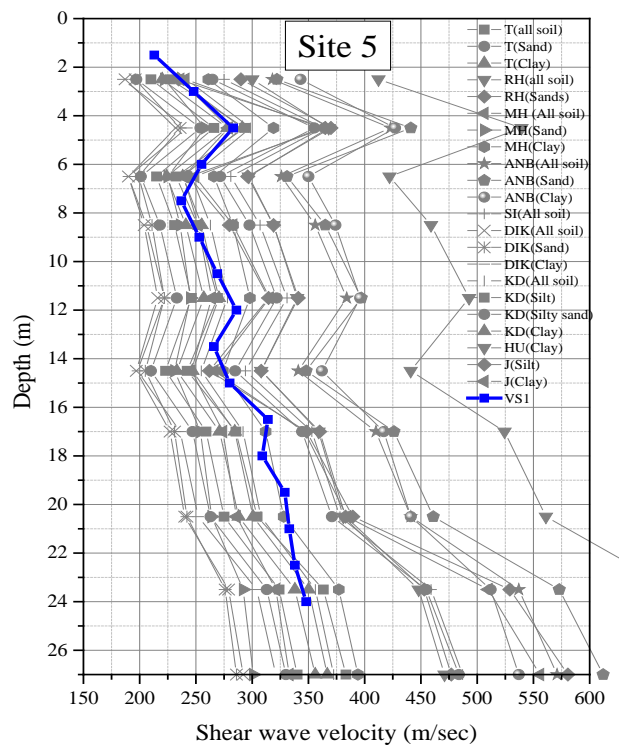

Fig. 7. Comparison of shear wave velocity estimated from SPT $\mathrm{N}$-value and measured response (Site 5).

The correlations available are intended to be used to obtain preliminary estimate of Vs where geophysical measurements are not available. These relations shall not be used as substitute for geophysical measurements, since, estimate from the relations can contain considerable uncertainties. However, where geophysical measurements are not available, these correlations may provide simple but crude method of estimating dynamic soil properties for the purpose of preliminary analysis. The available correlations shall be used very cautiously for engineering use in soft clay, silty clay deposits as observed for Site 1, Site 2 and Site
3. In addition to penetration resistance, estimation of Vs may be improved by introducing additional parameters such as confining stress (depth), geology (depositional environment, aging, etc.), and soil type.

\section{REFERENCES}

1) Anbazhagan, P., Kumar, A. and Sitharam, T. G. (2013): Seismic site classification and correlation between standard penetration test $\mathrm{N}$ value and shear wave velocity for Lucknow city in Indo-Gangetic basin, Pure and Applied Geophysics, 170, 299-318.

2) Chatterjee, K. and Choudhury, D. (2013): Variations in shear wave velocity and soil site class in Kolkata city using regression and sensitivity analysis, Natural Hazards, 69(3), 2057-2082.

3) Dikmen, U. (2009): Statistical Correlations of Shear Wave Velocity and Penetration Resistance for Soils, Journal of Geophysics and Engineering, 6(1), 61-72.

4) Hanumantharao, C. and Ramana, G. V. (2008): Dynamic Soil Properties for Microzonation of Delhi, India, Journal of Earth System Science, 117 (S2), 719-730.

5) Hasancebi, N. and Ulusay, R (2007): Empirical correlations between shear wave velocity and penetration resistance for ground shaking assessments, Bull Eng Geol Environ, 66, 203-213.

6) Jafari, M.K., Shafiee, A. and Razmkhah, A. (2002): Dynamic Properties of Fine Grained Soils in South of Tehran, Journal of Seismological Earthquake Engineering, 4, 25-35.

7) Jishnu, R.B., Naik, S.P., Patra, N.R. and Malik, J.N. (2013): Ground response analysis of Kanpur soil along Indo-Gangetic Plains, Soil Dynamics and Earthquake Engineering, 51, 47-57.

8) Maheswari, U. R., Boominathan, A. and Dodagoudar, G. R. (2010): Use of Surface Waves in Statistical Correlations of Shear Wave Velocity and Penetration Resistance of Chennai soils, Geotechnical and Geology Engineering, 28(2), 119-137.

9) Mhaske, S. Y. and Choudhury, D. (2010): GIS-based soil liquefaction susceptibility map of Mumbai city for earthquake events, Journal of Applied Geophysics, 70(3), 216-225.

10) Mhaske, S. Y. and Choudhury, D. (2011): Geospatial contour mapping of shear wave velocity for Mumbai city, Natural Hazards, 59 (1), 317-327.

11) Pitilakis, K.D., Anastasiadis, A. and Raptakis, D. (1992): Field and laboratory determination of dynamic properties of natural soil deposits, Proceedings of 10th World Conf. Earthquake Engineering, Rotterdam, 1275-1280.

12) Seed, H.B. and Idriss, I. M. (1981): Evaluation of liquefaction potential sand deposits based on observation of performance in previous earthquakes., In situ testing to evaluate liquefaction susceptibility, ASCE National Convention, Missouri, Preprint, 81-544.

13) Shukla, J. and Choudhury, D. (2012): Seismic hazard and site-specific ground motion for typical ports of Gujarat, Natural Hazards, 60 (2), 541-565.

14) Thaker, T.P. and Rao, K.S. (2011): Development of statistical correlations between shear wave velocity and penetration resistance using MASW technique, Geo- Innovation Addressing Global Challenges, Toronto, Ontario, Canada.

15) ASCE/SEI 7-05 (2005): Minimum Design Loads for Buildings and Other Structures, doi: 10.1061/978078441291 